\title{
A New Steganography Method for Gray Level Images using Parity Checker
}

\author{
Rajkumar \\ Assistant Professor \\ Deptt. Of Comp. Sc. \& Engg. \\ UIET, MD University, Rohtak-124001 \\ (INDIA) \\ Rahul Rishi \\ Associate Professor \\ Department of Comp. Sci. \& Engg, \\ TITS, Bhiwani-127021 (INDIA)
}

\author{
Sudhir Batra \\ Professor \\ Department of Mathematics \\ DCRUST, Murthal-131039 \\ (INDIA)
}

\begin{abstract}
In the present study, we present a new steganography technique for hiding data in images using parity checker. This method uses the concept of odd and even parity for insertion and retrieval of message. This method is an improvement over earlier methods like least significant bit method and $6^{\text {th }}, 7^{\text {th }}$ bit method [1] for hiding information in images. Our method retains the advantages of above methods but discards the disadvantages of above methods and provides us the optimal results.
\end{abstract}

\section{Keywords}

Parity Checker, Even Parity, Odd Parity, Pseudo Random Number Generator, Steganalysis

\section{INTRODUCTION}

Steganography is an art and science of hiding information in some cover media. The term originated from Greek roots that literally means "covered writing" [2]. Steganography has been used since ancient times, for example people practiced it by etching messages in wooden tablets and covered with wax. They used tattooing a shaved messenger's head, letting his hair grow back and then saving it again when he arrived at his contact point to reveal the message. Different types of stenographic techniques have been used that employ invisible inks, microdots, character etc. [3].

Digital steganography uses the digital objects such as image, video, music or any other computer file for hiding the data. The idea was first given by Simmons in 1983[4]. Steganography is different from cryptography; the latter is about concealing the content of message whereas former is about concealing the existence of message itself [5].

A most popular and oldest technique for hiding data in digital image is the Least Significant Bit Method Technique [6]. One of the major disadvantages associated with LSB techniques is that the hidden message can be destroyed by the intruder by changing the LSB of all image pixels. In this way, hidden message can be destroyed but the change in image quality is in the range of +1 to -1 at each pixel position. The algorithm designed by Parvinder et al. [7] removes the disadvantage of least significant bit method technique by using $6^{\text {th }}$ and $7^{\text {th }}$ bit of pixel value for message insertion. But the chance of message insertion at pseudo random location at first instance using this algorithm (as described by Parvinder et al.) is only $49 \%$ which in itself is a disadvantage. In spite of all, one common disadvantage of above mentioned algorithms for insertion and retrieval of message is the stress on specific bits (like $6^{\text {th }}$ and $7^{\text {th }}$ bit etc.) which makes the stegananalysis very easy. In the present study, we used the concept of even and odd parity and stressed on whole pixel rather than specific bits by using the parity checker. In our algorithm, the chance of message insertion at the pseudo random location at first instance is $98.82 \%$ as compared with Parvinder et al. that provides only $49 \%$ chance. This is near about optimal solution and an improvement over previous methods.

\section{DESCRIPTION OF PROPOSED METHOD}

In our method, we used the concept of even and odd parity by using the parity checker. As we already know that even parity means that the pixel value contains even number of 1 's and odd parity means that the pixel value contains odd number of 1 's. We inserted ' 0 ' at a pixel value where pixel value had odd parity and if odd parity is not present over there than we made the odd parity by adding or subtracting ' 1 ' to the pixel value. Similarly, we inserted ' 1 ' at a pixel value if it had even parity. In case, if even parity is not present at that location then we made even parity over that location by adding or subtracting ' 1 '. In this way we can insert ' 0 ' or ' 1 ' at any location. The insertion process is shown in figure $2\left(a_{1} \& a_{2}\right)$.

For Retrieval of message, again we used the parity checker. If odd parity is present at the selected location then ' 0 ' is message bit, else message bit is ' 1 '. Retrieval process was repeated for all locations where message bits were hidden. In this way, we retrieved the message bits from all the locations where the message bit were inserted. The retrieval process is shown in Figure 2 (b) 


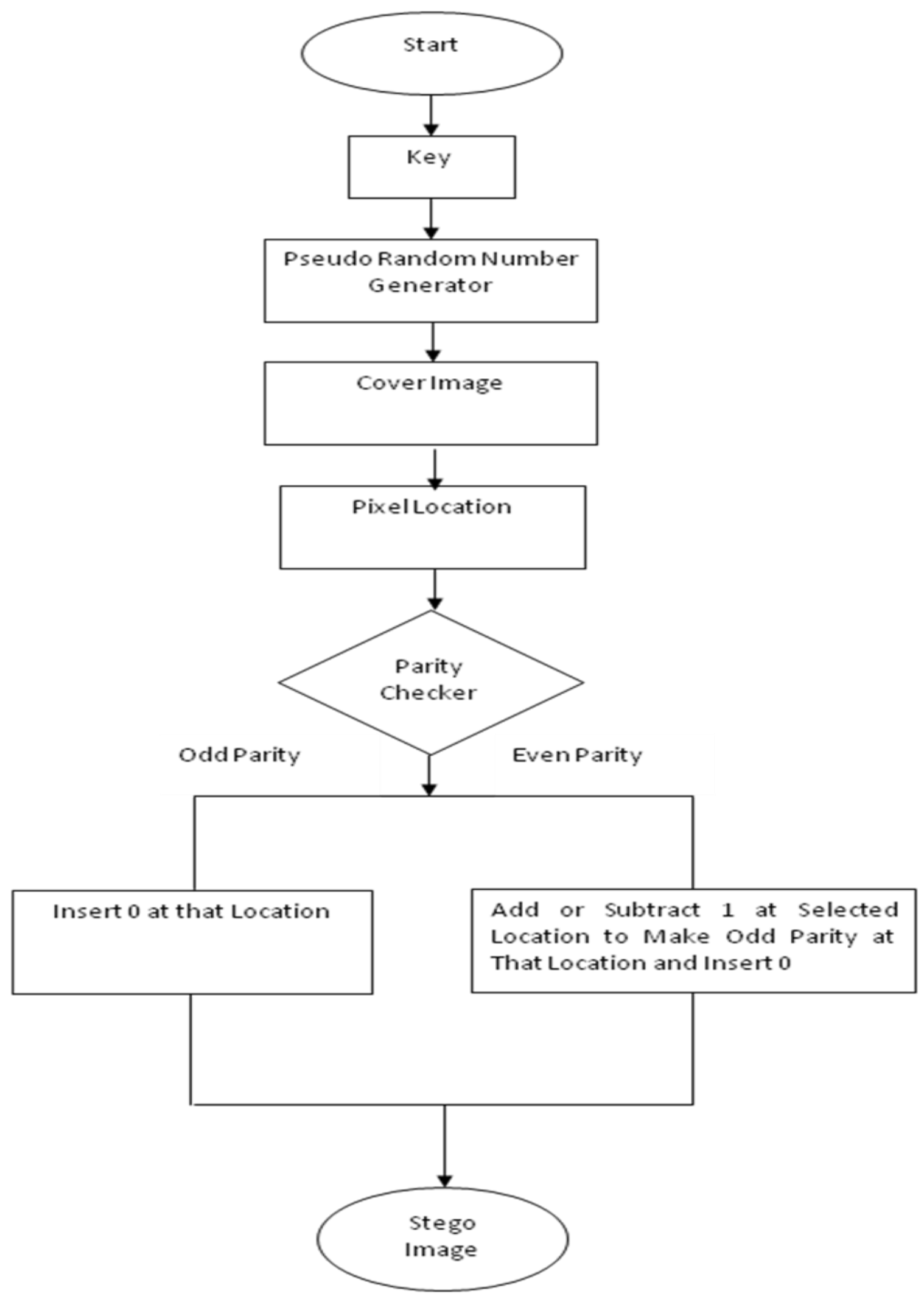

Figure $2\left(a_{1}\right)$ : Flow chart depicting the Insertion of ' 0 ' 


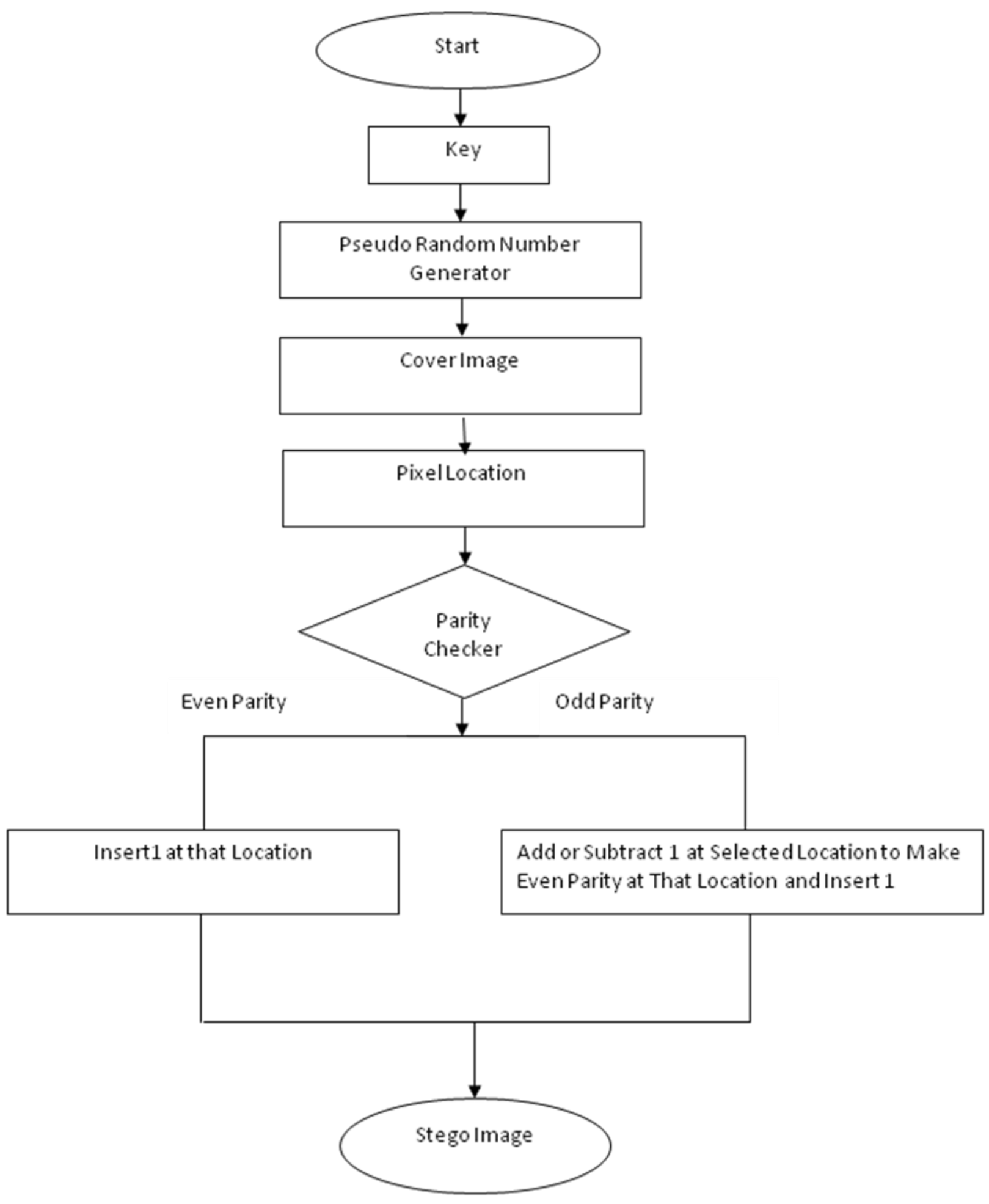

Figure $2\left(a_{2}\right)$ : Flow chart depicting the Insertion of ' 1 ' 


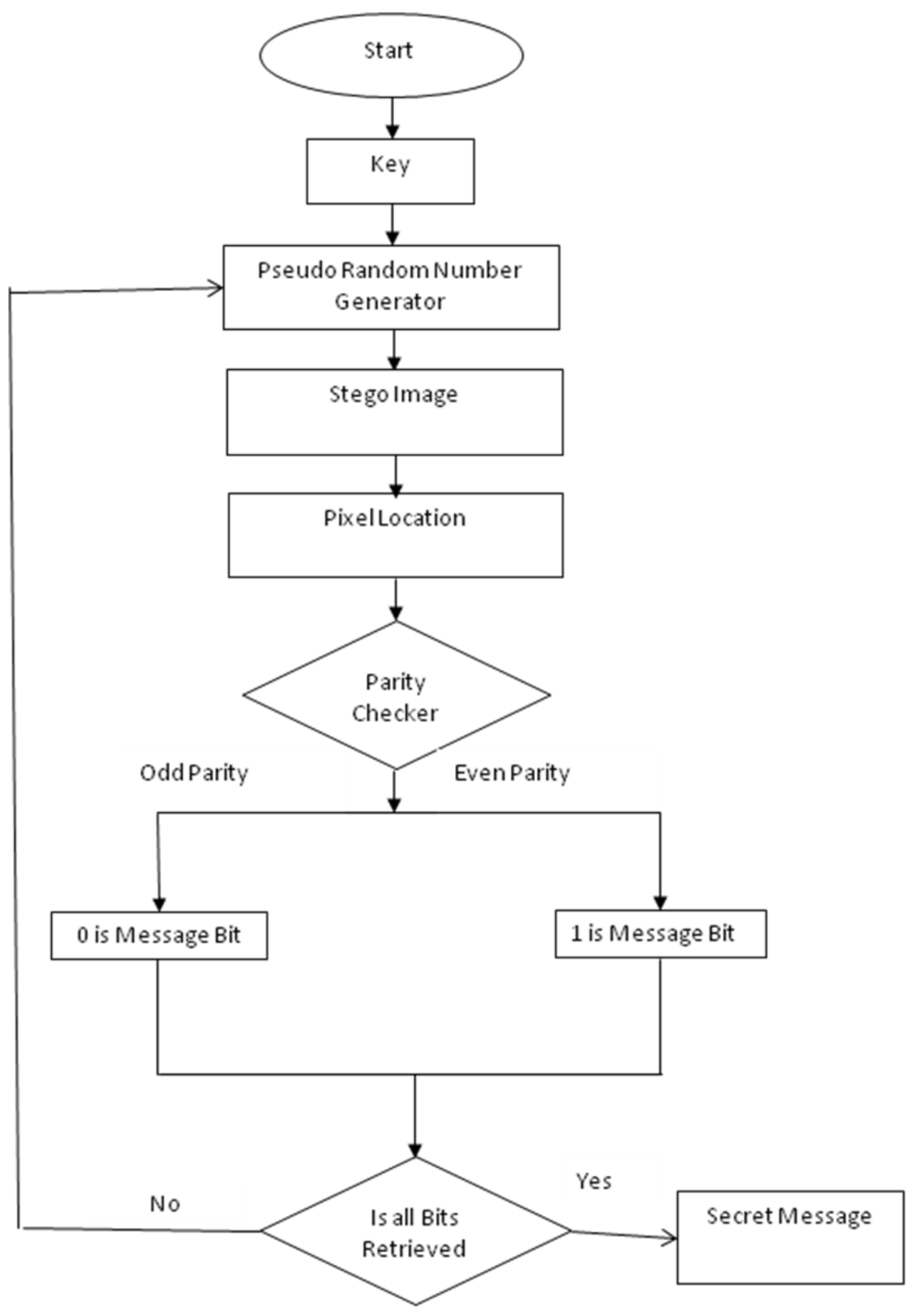

Figure 2(b): Flow chart depicting the retrieval process 


\section{ALGORITHM}

\subsection{Assumption}

(i) Sender and recipient agree on the cover object in which message is supposed to be hidden.

(ii) Both sender and recipient agree on the same pseudo-random key to decide the random locations where message is to be inserted.

\subsection{Insertion Algorithm}

(i) Find the pseudo-random location (L) in cover image from secret key to insert the message bit. (For detail see [7] and [8]).

Check whether at location (L); pixel value is 00000000 OR 11111111. If yes, ignore this location and go to step (i). Here, we are ignoring these boundary values because the change may be +2 or -2 in pixel values which is to be avoided.

(iii) If we want to insert 0 then go to step (iv) else go to step (v).

(iv) (a) Check whether at location (L) there exists odd parity. If yes, insert 0 at location ' $\mathrm{L}$ ', go to End. If No, go to step (b)

(b) Make the odd parity by adding or subtracting 1 and insert 0 . Go to END

(v) (a) Check whether at location ' $L$ ' there exists even parity. If yes, insert 1 at location (L) and go to END. If No, go to step (b).

(b) Make the even parity by adding or subtracting 1, insert 1 and go to END.

\section{(vi) END}

\subsection{Retrieval Algorithm}

(i) Trace out the location (L) from the same secret key as used for insertion of message.

(ii) Pixel value is equal to $00000000 \mathrm{OR}$ 11111111 ? If yes, then it is invalid address. Go to step (i)

(iii) Check whether at location (L):

(a) If there is odd parity then 0 is message bit.

(b) If there is even parity then 1 is message bit

(iv) END

\section{CHANGE IN PIXEL DURING INSERTION OF MESSAGE}

It is obvious from the above described algorithm that how various pixel values changed during insertion process. The corresponding change in pixel values while inserting 0 and 1 is shown in Table 1 and 2 respectively.

\section{RESULTS AND CONCLUSION}

5.1 The following results obtained from Table (I) and Table (II) tell us how our method is better than previous methods.

(i) The message bit will be inserted at the pseudo random location at first

chance $=506 / 512 * 100=98.82 \%$

(ii) Chance when message is inserted, no change in pixel value is required

$=254 / 506 * 100=50.19 \%$

5.2 The comparison of our method with $6^{\text {th }}, 7^{\text {th }}$ bit method for hiding the messages in images is shown in Table 3.

Table 1: Change in pixel value after insertion of ' 0 '

\begin{tabular}{|c|c|c|c|c|}
\hline $\begin{array}{c}\text { Decimal } \\
\text { Value }\end{array}$ & $\begin{array}{l}\text { Pixel } \\
\text { Value } \\
\text { Before } \\
\text { Insertion }\end{array}$ & $\begin{array}{l}\text { Comment } \\
\text { By Parity } \\
\text { Checker }\end{array}$ & $\begin{array}{l}\text { Pixel } \\
\text { Value } \\
\text { After } \\
\text { Insertion } \\
\text { an of '0' }\end{array}$ & $\begin{array}{l}\text { Change in } \\
\text { Pixel } \\
\text { Value \& } \\
\text { Comment } \\
\text { for } \\
\text { Insertion } \\
\text { of '0' }\end{array}$ \\
\hline 0 & 00000000 & $\mathrm{BV}$ & 00000000 & $\begin{array}{l}\text { NC, Invalid } \\
\text { Location }\end{array}$ \\
\hline 1 & 00000001 & Odd Parity & 00000001 & NC, Insert \\
\hline 2 & 00000010 & Odd Parity & 00000010 & $\mathrm{NC}$, Insert \\
\hline 3 & 00000011 & $\begin{array}{l}\text { Even } \\
\text { Parity }\end{array}$ & 00000010 & -1 , Insert \\
\hline 4 & 00000100 & Odd Parity & 00000100 & NC, Insert \\
\hline 5 & 00000101 & $\begin{array}{l}\text { Even } \\
\text { Parity }\end{array}$ & 00000100 & -1 , Insert \\
\hline 6 & 00000110 & $\begin{array}{l}\text { Even } \\
\text { Parity }\end{array}$ & 00000111 & +1 Insert \\
\hline 7 & 00000111 & Odd Parity & 00000111 & $\mathrm{NC}$, Insert \\
\hline 8 & 00001000 & Odd Parity & 00001000 & $\mathrm{NC}$, Insert \\
\hline 9 & 00001001 & $\begin{array}{l}\text { Even } \\
\text { Parity }\end{array}$ & 00001000 & -1 , Insert \\
\hline 10 & 00001010 & $\begin{array}{l}\text { Even } \\
\text { Parity }\end{array}$ & 00001011 & +1 , Insert \\
\hline 11 & 00001011 & Odd Parity & 00001011 & NC, Insert \\
\hline 12 & 00001100 & $\begin{array}{l}\text { Even } \\
\text { Parity }\end{array}$ & 00001011 & -1 , Insert \\
\hline
\end{tabular}




\begin{tabular}{|c|l|l|l|l|}
\hline 13 & 00001101 & Odd Parity & 00001101 & NC, Insert \\
\hline 14 & 00001110 & Odd Parity & 00001110 & NC, Insert \\
\hline 15 & 00001111 & $\begin{array}{l}\text { Even } \\
\text { Parity }\end{array}$ & 00001000 & +1, Insert \\
\hline- & - & - & - & - \\
\hline- & - & - & - & - \\
\hline- & - & - & - & - \\
\hline 127 & 01111111 & Odd Parity & 01111111 & NC, Insert \\
\hline 128 & 10000000 & Odd Parity & 10000000 & NC, Insert \\
\hline- & - & - & - & - \\
\hline- & - & - & - & - \\
\hline- & - & - & - & - \\
\hline 254 & 11111110 & Odd Parity & 11111110 & NC, Insert \\
\hline 255 & 111111111 & $\begin{array}{l}\text { Even } \\
\text { Parity }\end{array}$ & 11111111 & NC, Invalid \\
& & \multicolumn{2}{|l}{} \\
\hline
\end{tabular}

$\mathrm{BV}=$ Boundary values

$\mathrm{NC}=$ No Change

Table 2: Change in pixel value after insertion of ' 1 '

\begin{tabular}{|c|c|c|c|c|}
\hline $\begin{array}{c}\text { Decimal } \\
\text { Value }\end{array}$ & $\begin{array}{c}\text { Pixel } \\
\text { Value } \\
\text { Before } \\
\text { Insertion }\end{array}$ & $\begin{array}{c}\text { Comment } \\
\text { by Parity } \\
\text { checker }\end{array}$ & $\begin{array}{c}\text { Pixel } \\
\text { Value } \\
\text { After } \\
\text { Insertio } \\
\text { n of '1' }\end{array}$ & $\begin{array}{l}\text { Change in } \\
\text { Pixel value \& } \\
\text { Comment for } \\
\text { insertion of }\end{array}$ \\
\hline 0 & 00000000 & BV & $\begin{array}{l}0000000 \\
0\end{array}$ & $\begin{array}{l}\text { NC,Invalid } \\
\text { Location }\end{array}$ \\
\hline 1 & 00000001 & Odd Parity & $\begin{array}{l}0000000 \\
0\end{array}$ & $\begin{array}{l}-1, \\
\text { Invalid Location }\end{array}$ \\
\hline 2 & 00000010 & Odd Parity & $\begin{array}{l}0000001 \\
1\end{array}$ & +1 , Insert \\
\hline 3 & 00000011 & $\begin{array}{l}\text { Even } \\
\text { Parity }\end{array}$ & $\begin{array}{l}0000001 \\
1\end{array}$ & NC, Insert \\
\hline 4 & 00000100 & Odd Parity & $\begin{array}{l}0000010 \\
1\end{array}$ & +1 , Insert \\
\hline 5 & 00000101 & $\begin{array}{l}\text { Even } \\
\text { Parity }\end{array}$ & $\begin{array}{l}0000010 \\
1 \\
\end{array}$ & $\mathrm{NC}$, Insert \\
\hline 6 & 00000110 & $\begin{array}{l}\text { Even } \\
\text { Parity }\end{array}$ & $\begin{array}{l}0000011 \\
0\end{array}$ & $\mathrm{NC}$, Insert \\
\hline 7 & 00000111 & Odd Parity & $\begin{array}{l}0000011 \\
0\end{array}$ & -1 , Insert \\
\hline 8 & 00001000 & Odd Parity & $\begin{array}{l}0000100 \\
0 \\
\end{array}$ & +1 , Insert \\
\hline 9 & 00001001 & $\begin{array}{l}\text { Even } \\
\text { Parity }\end{array}$ & $\begin{array}{l}0000100 \\
0\end{array}$ & $\mathrm{NC}$, Insert \\
\hline 10 & 00001010 & $\begin{array}{l}\text { Even } \\
\text { Parity }\end{array}$ & $\begin{array}{l}0000110 \\
0 \\
\end{array}$ & NC, Insert \\
\hline 11 & 00001011 & Odd Parity & $\begin{array}{l}0000110 \\
0\end{array}$ & +1 , Insert \\
\hline 12 & 00001100 & $\begin{array}{l}\text { Even } \\
\text { Parity }\end{array}$ & $\begin{array}{l}0000111 \\
1 \\
\end{array}$ & $\mathrm{NC}$, Insert \\
\hline 13 & 00001101 & Odd Parity & 0000111 & -1 , Insert \\
\hline
\end{tabular}

\begin{tabular}{|c|c|c|c|c|}
\hline & & & 1 & \\
\hline 14 & 00001110 & Odd Parity & $\begin{array}{l}0000111 \\
0\end{array}$ & +1, Insert \\
\hline 15 & 00001111 & $\begin{array}{l}\text { Even } \\
\text { Parity }\end{array}$ & $\begin{array}{l}0000100 \\
0\end{array}$ & $\mathrm{NC}$, Insert \\
\hline- & - & - & - & - \\
\hline- & - & - & - & - \\
\hline- & - & - & - & - \\
\hline 127 & 01111111 & Odd Parity & $\begin{array}{l}0111111 \\
0\end{array}$ & -1,Insert \\
\hline 128 & 10000000 & Odd Parity & $\begin{array}{l}1000000 \\
1\end{array}$ & +1 , Insert \\
\hline- & - & - & - & - \\
\hline- & - & - & - & - \\
\hline- & - & - & - & - \\
\hline 254 & 111111110 & Odd Parity & $\begin{array}{l}1111111 \\
1\end{array}$ & $\begin{array}{l}+1 \text {, Invalid } \\
\text { location }\end{array}$ \\
\hline 255 & 111111111 & $\begin{array}{l}\text { Even } \\
\text { Parity }\end{array}$ & $\begin{array}{l}1111111 \\
1\end{array}$ & $\begin{array}{l}\text { NC,Invalid } \\
\text { location }\end{array}$ \\
\hline
\end{tabular}

Table 3: Comparison between methods described by Rajkumar et al. and Parvinder et al.

\begin{tabular}{|l|c|l|}
\hline Method & $\begin{array}{l}\text { Message Bit Insertion at } \\
\text { pseudorandom location at } \\
\text { First Chance }\end{array}$ & $\begin{array}{l}\text { No Change } \\
\text { in Pixel } \\
\text { Value when } \\
\text { Message bit } \\
\text { is inserted }\end{array}$ \\
\hline $\begin{array}{l}\text { Parvinder } \\
\text { et al. }\end{array}$ & $49 \%$ & $50 \%$ \\
\hline $\begin{array}{l}\text { Rajkumar } \\
\text { et al. }\end{array}$ & $98.82 \%$ & $50.19 \%$ \\
\hline
\end{tabular}

So, from the above discussion, we can say that our method is better than previous methods like $6^{\text {th }}$, 7 th bit method for the following reasons:

(a) It provides greater chances i.e. $98.82 \%$ for message insertion.

(b) Change in image required is less than previous methods.

(c) Steganylysis is difficult in our method because our stress is a whole pixel rather than specific bits as used by previous methods.

\section{REFERENCE}

[1] Parvinder, Sudhir Batra and H R Sharma, "Evaluating the Performance of Message Hidden in First and Second Bit Plane, W SEAS Transaction on Information 
Science and Technology, Vol. 2, No. 89, PP 12201222, Aug. 2005.

[2] A. Gutub, M. Fattani, "A Novel Arabic Text Stegnography Method Using Letter Points and Extension", WASET International Conference on Computer, Information and System Science and Engineering (ICCISSE), Vienna, Austria, May 25-27, 2007.

[3]. RJ Anderson, "Stretching the Limit of Stegnography", In Information Hiding, Springer Lecture Notes in Computer Science, Vol. 1174, pp 39-48, 1996.

[4]. G J Simmons, "The Prisoners Problem and the Subliminal Chaunell", Proceedings of cypto' 83, Plenum Press, pp 51-67, 1983.
[5] RJ Anderson, FAP Petitcolas, "On the Limits of Stegnography" IEE Journal on Selected Areas in Communications, Vol. 16 No. 4, PP 474-481, May, 1998.

[6]. Neil F Johnson, Sushil Jajodia, "Exploring Stenography: Seeing the Unseen", IEEE Computer, pp 26-34, Feb 1998.

[7]. E Franz, A Jerichow, S Moller, A Pfitznaun, I Stierand, "Computer Based Stegnography", Information Hiding, Springer Lecture Notes in Computer Science vol. 1174, pp 7-21, 1996.

[8] Yeuan-Kuen Lee, Ling - Hwei chen, "A secure Robust Image Stegnography Model", $10^{\text {th }}$ National Conference on Information Security, Hualien, Taiwan, pp 275-284, May, 2000. 